\title{
Identification of QTLs associated with oil content and mapping FAD2 genes and their relative contribution to oil quality in peanut (Arachis hypogaea L.)
}

Manish K Pandey ${ }^{1,2,3+}$, Ming Li Wang ${ }^{4+}$, Lixian Qiao ${ }^{1,3,5+}$, Suping Feng ${ }^{1,3,6}$, Pawan Khera ${ }^{1,2,3}$, Hui Wang ${ }^{1,3,7}$, Brandon Tonnis ${ }^{4}$, Noelle A Barkley ${ }^{4}$, Jianping Wang ${ }^{8}$, C Corley Holbrook ${ }^{9}$, Albert K Culbreath ${ }^{3}$, Rajeev K Varshney ${ }^{2^{*}}$ and Baozhu Guo ${ }^{1,3^{*}}$

\begin{abstract}
Background: Peanut is one of the major source for human consumption worldwide and its seed contain approximately 50\% oil. Improvement of oil content and quality traits (high oleic and low linoleic acid) in peanut could be accelerated by exploiting linked markers through molecular breeding. The objective of this study was to identify QTLs associated with oil content, and estimate relative contribution of FAD2 genes (ahFAD2A and ahFAD2B) to oil quality traits in two recombinant inbred line (RIL) populations.

Results: Improved genetic linkage maps were developed for S-population (SunOleic 97R $\times$ NC94022) with 206 (1780.6 cM) and T-population (Tifrunner $\times$ GT-C20) with 378 (2487.4 cM) marker loci. A total of 6 and 9 QTLs controlling oil content were identified in the S- and T-population, respectively. The contribution of each QTL towards oil content variation ranged from 3.07 to $10.23 \%$ in the S-population and from 3.93 to $14.07 \%$ in the T-population. The mapping positions for ahFAD2A (A sub-genome) and ahFAD2B (B sub-genome) genes were assigned on a09 and b09 linkage groups. The ahFAD2B gene (26.54\%, 25.59\% and 41.02\% PVE) had higher phenotypic effect on oleic acid (C18:1), linoleic acid (C18:2), and oleic/linoleic acid ratio (O/L ratio) than ahFAD2A gene (8.08\%, 6.86\% and 3.78\% PVE). The FAD2 genes had no effect on oil content. This study identified a total of 78 main-effect QTLs (M-QTLs) with up to 42.33\% phenotypic variation (PVE) and 10 epistatic QTLs (E-QTLs) up to 3.31\% PVE for oil content and quality traits.

Conclusions: A total of 78 main-effect QTLS (M-QTLS) and 10 E-QTLs have been detected for oil content and oil quality traits. One major QTL (more than 10\% PVE) was identified in both the populations for oil content with source alleles from NC94022 and GT-C20 parental genotypes. FAD2 genes showed high effect for oleic acid (C18:1), linoleic acid (C18:2), and O/L ratio while no effect on total oil content. The information on phenotypic effect of FAD2 genes for oleic acid, linoleic acid and O/L ratio, and oil content will be applied in breeding selection.
\end{abstract}

Keywords: Peanut, Genetic map, QTL analysis, Oil content, Oleic acid, Linoleic acid, O/L ratio, FAD2 genes

\footnotetext{
* Correspondence: r.k.varshney@cgiar.org; baozhu.guo@ars.usda.gov

${ }^{\dagger}$ Equal contributors

${ }^{2}$ International Crops Research Institute for the Semi-Arid Tropics (ICRISAT),

Hyderabad, India

'US Department of Agriculture-Agricultural Research Service, Crop Protection

and Management Research Unit, Tifton, GA, USA

Full list of author information is available at the end of the article
} 


\section{Background}

Peanut (Arachis hypogaea L.) is mostly grown in semiarid tropic (SAT) regions in over 100 countries of Asia, Africa and Americas. In 2012, the global production was $41.18 \mathrm{~m}$ tons from an area of $24.70 \mathrm{~m}$ ha [1]. It is one of the main oil crops of the world averaging about $50 \%$ oil content and it could be as low as less than 40\% [2]. In countries such as China and India, peanuts are primarily crushed for oil, and thus increasing oil content is the breeding priority. In the United States, peanuts are primarily used as edible products (such as peanut butter, roasted and salted peanuts, confectionaries, or in-shell peanuts), and lowering the oil content is a breeding objective. High $\mathrm{O} / \mathrm{L}$ ratio (ratio of oleic and linoleic acid) is the most desired oil quality trait as it provide increased shelf life and health benefits to manufacturers and consumers, respectively. Fatty acid desaturase (FAD2) catalyzes the conversion of oleic acid to linoleic acid by adding a double bond to oleic acid [3]. This enzyme is encoded by two homeologous genes, ahFAD2A and ahFAD2B, located on the A and B sub-genomes, respectively [4-6]. Both the FAD2 genes have 99\% sequence homology and inactivation of both copies of the enzymes results in high $\mathrm{O} / \mathrm{L}$ ratio in mutants. The mutant ahFAD2A gene had substitution (G:C to A:T) and ahFAD2B gene had insertion (A:T) of one base pair. These mutations led to accumulation of more oleic acid (C18:1) and less linoleic acid (C18:2) making the peanut oil with high $\mathrm{O} / \mathrm{L}$ ratio.

Oleic (C18:1) (monounsaturated) and linoleic acids (C18:2) (diunsaturated) together account for $80 \%$ of total oil content in peanut [7]. The improved shelf life of peanut oil is because of multifold (10 fold) higher anti-oxidative stability in presence of high oleic acid (C18:1) as compared to presence of high linoleic acid [8]. Consuming peanut products using the seed containing high oleic acid has several health benefits such as reduction of serum cholesterol level, suppression of tumorigenesis and amelioration of inflammatory diseases $[9,10]$. Both the fatty acids i.e., oleic acid (C18:1) and linoleic acid (C18:2) are known to lower the level of bad cholesterol (low-density lipoprotein, LDL). The oleic acid (C18:1) provides more advantage over linoleic acid (C18:2) by not affecting good cholesterol (high-density lipoprotein, HDL) levels [11]. This is because the saturated fatty acids are known to be hypercholesterolemic, polyunsaturated fatty acids are hypocholesterolemic while monounsaturated fatty acids are known to be neutral [12]. Moreover, oil with higher unsaturated fatty acids allows heating without smoking at high temperatures, which leads to faster cooking and less oil absorption by the cooked food [13]. In addition, higher concentration of polyunsaturated fatty acids (PUFA) such as linoleic and linolenic acids makes the cooked product more susceptible to rancidity and decreases flavor rapidly along with shortening the shelf life. Therefore, breeding peanuts with high $\mathrm{O} / \mathrm{L}$ ratio along with high oil content or low oil content will have direct impacts on profitability of growers, peanut industry and consumer preferences such as low fat foods.

The challenge before the breeding program is to target oil content and $\mathrm{O} / \mathrm{L}$ ratio in addition to yield enhancement [14-16]. The effort led to identification of the first mutant (F435) with high oleic acid (C18:1) at the University of Florida. The difference in $\mathrm{O} / \mathrm{L}$ ratio obtained between existing peanut germplasm is very low (only 1.0 to $2.5 \mathrm{O} / \mathrm{L}$ ratio) as compared to the high oleic mutant (up to $40.0 \mathrm{O} / \mathrm{L}$ ratio) [17]. This mutant line was then utilized for development of a series of breeding lines with high oleic acid $[18,19]$.

Oil content in peanut seeds is a complex trait controlled by a number of genes with significant environmental influences. Molecular markers have been used to discover quantitative trait locus (QTL) or chromosomal regions associated with seed oil in other oil crops [20]. The identification of markers or QTL for peanut oil will have potential application in molecular breeding, which could facilitate the development of high or low oil content peanuts with the high oleic trait. In the present study, two recombinant inbred line (RIL) populations used to address the following objectives: (1) to improve the genetic linkage maps developed by Qin et al. [21], (2) to identify QTL for oil content and quality, (3) to map the FAD2 on the peanut genome and (4) to determine the effects of $F A D 2$ genes on oil content and oil quality.

\section{Results}

\section{Development of improved genetic maps}

Two recombinant inbred line (RIL) populations namely S-population (SunOleic 97R $\times$ NC94022) and T-population (Tifrunner $\times$ GT-C20) were used to construct genetic maps with 172 and 239 loci, respectively [21]. The present study further improved these two genetic maps to 206 and 378 marker loci for the S-population and the T-population (Additional files 1 and 2), respectively. For the S-population, 206 mapped loci were distributed on 20 linkage groups (LGs) covering a total genome distance of $1780.6 \mathrm{cM}$ and achieved a map density of $9.6 \mathrm{cM} /$ loci. Similarly for the T-population, 378 loci were mapped onto 20 linkage groups covering a total map distance of $2487.4 \mathrm{cM}$ with a map density of $7.0 \mathrm{cM} /$ loci (Table 1, Additional files 3 and 4). The number of mapped marker loci per LG were ranged from 3 loci (a02, a08 and b05) to 18 loci (a03) in the S-population while 10 loci (b03) to 35 loci (a04) in the T-population. Similarly, the individual length of LGs ranged from $29.9 \mathrm{cM}$ (a02) to $244.3 \mathrm{cM}$ (b09) in the S-population, and 52.4 cM (a07) to $200.9 \mathrm{cM}$ 
Table 1 Important features of the genetic maps constructed for the S-population and the T-population

\begin{tabular}{|c|c|c|c|c|c|c|c|}
\hline \multirow{2}{*}{$\begin{array}{l}\mathrm{S} \\
\text { No }\end{array}$} & \multirow{2}{*}{$\begin{array}{l}\text { Linkage } \\
\text { group }\end{array}$} & \multicolumn{3}{|c|}{ S-population } & \multicolumn{3}{|c|}{ T-population } \\
\hline & & $\begin{array}{l}\text { Total map distance } \\
\text { (cM) }\end{array}$ & Mapped loci & $\begin{array}{l}\text { Map density } \\
\text { (cM/loci) }\end{array}$ & $\begin{array}{l}\text { Total map distance } \\
\text { (cM) }\end{array}$ & Mapped loci & $\begin{array}{l}\text { Map density } \\
\text { (cM/loci) }\end{array}$ \\
\hline \multicolumn{8}{|c|}{ A sub-genome linkage groups } \\
\hline 1 & $\mathrm{a} 01$ & 61.1 & 13 & 4.7 & 179.1 & 22 & 8.1 \\
\hline 2 & $\mathrm{a} 02$ & 29.9 & 3 & 10.0 & 117.5 & 12 & 9.8 \\
\hline 3 & $\mathrm{a} 03$ & 66.5 & 18 & 3.7 & 150.2 & 31 & 4.8 \\
\hline 4 & a04 & 103.9 & 8 & 13.0 & 121.7 & 35 & 3.5 \\
\hline 5 & a05 & 150.4 & 17 & 8.8 & 102.5 & 24 & 4.3 \\
\hline 6 & $\mathrm{a} 06$ & 99.2 & 6 & 16.5 & 158.7 & 26 & 6.1 \\
\hline 7 & $\mathrm{a} 07$ & 118.1 & 17 & 6.9 & 52.4 & 13 & 4.0 \\
\hline 8 & a08 & 28.5 & 3 & 9.5 & 200.9 & 28 & 7.2 \\
\hline 9 & a09 & 74.4 & 17 & 4.4 & 77.0 & 18 & 4.5 \\
\hline 10 & a10 & 67.4 & 8 & 8.4 & 82.1 & 16 & 5.1 \\
\hline \multicolumn{8}{|c|}{ B sub-genome linkage groups } \\
\hline 11 & b01 & 68.4 & 12 & 5.7 & 87.0 & 13 & 6.7 \\
\hline 12 & b02 & 69.7 & 8 & 8.7 & 115.8 & 20 & 5.3 \\
\hline 13 & b03 & 156.7 & 12 & 13.1 & 120.1 & 10 & 12.0 \\
\hline 14 & b04 & 91.1 & 13 & 7.0 & 190.2 & 21 & 9.1 \\
\hline 15 & b05 & 62.3 & 3 & 20.8 & 154.8 & 13 & 11.9 \\
\hline 16 & b06 & 39.0 & 4 & 9.8 & 83.3 & 13 & 6.4 \\
\hline 17 & b07 & 157.6 & 12 & 13.1 & 134.0 & 18 & 7.4 \\
\hline 18 & b08 & 54.8 & 11 & 5.0 & 101.3 & 16 & 6.3 \\
\hline 19 & b09 & 244.3 & 15 & 16.3 & 124.4 & 13 & 9.6 \\
\hline 20 & b10 & 37.3 & 6 & 6.2 & 134.4 & 16 & 8.4 \\
\hline \multicolumn{2}{|c|}{ Total /mean } & 1780.6 & 206 & 9.6 & 2487.4 & 378 & 7.0 \\
\hline
\end{tabular}

(a08) in the T-population. Of the total 206 mapped loci in the S-population, 110 loci could be mapped on the A sub-genome with a total map distance of $799.4 \mathrm{cM}$ and 96 loci were mapped on the B sub-genome with a map distance of $981.2 \mathrm{cM}$. Similarly in the T-population, 225 and 153 loci were mapped on the $\mathrm{A}$ and the $\mathrm{B}$ sub-genome, resulting in the total map distance of 1242.1 and $1245.2 \mathrm{cM}$, respectively.

\section{Identification of main-effect QTLs (M-QTLs) by QTLCartographer}

Phenotypic data obtained for two seasons for oil content and quality traits were analyzed together with genotypic data for both the populations using Windows QTLCartographer. QTL analysis resulted in identification of a total of 27 (S-population) and 29 (T-population) M-QTLs for oil content and quality traits with PVE ranging up to $42.33 \%$ and $28.98 \%$, respectively (Table 2, Figures 1 and 2). The highest logarithm of odds (LOD) value could be observed for $\mathrm{O} / \mathrm{L}$ ratio (up to 118.87) in the S-population and for linoleic acid (C18:2) (up to 15.8) in the T-population.
Further, the LOD value ranged from 2.85 to 9.27 and 2.53 to 8.00 for oil content in the S- and the T-population, respectively (Table 2). Of the 27 and 29 QTLs identified for oil content and quality traits in S- and T-population, seven and six QTLs were major QTLs (>10\% PVE), respectively (Additional files 5 and 6).

For oleic acid (C18:1), a total of eight M-QTLs in the $\mathrm{S}$-population and nine M-QTLs in the T-population were identified with PVE up to $27.54 \%$ and $28.98 \%$, respectively (Table 2). The ahFAD2A (7.76\% and 8.40\%) and $a h F A D 2 B$ (27.54\% and $25.54 \%$ ) showed consistent high contributions in both years in the S-population, while ahFAD2A (28.98\% and $12.13 \%$ ) contributed in similar way in the T-population. The $a h F A D 2 A$ and $a h F A D 2 B$ genes contributed for high oleic acid (C18:1) and the contributing mutant allele came from the 'SunOleic 97R' parent in the $\mathrm{S}$-population. Similarly in the T-population, the ahFAD2A gene contributed for high oleic acid (C18:1) and the contributing mutant allele came from 'Tifrunner'. In terms of consistency of the QTLs, the QTLs identified in both years (2010 and 2011) were considered as "consistent" QTLs. 
Table 2 Summary of main-effect QTLs (M-QTLs) identified by QTLCartographer in the S-population and the T-population

\begin{tabular}{|c|c|c|c|c|c|c|c|c|}
\hline \multirow[t]{2}{*}{ Traits } & \multicolumn{4}{|c|}{ S-population } & \multicolumn{4}{|c|}{ T-population } \\
\hline & $\begin{array}{l}\text { QTLs } \\
\text { identified }\end{array}$ & $\begin{array}{l}\text { LOD value } \\
\text { range }\end{array}$ & $\begin{array}{l}\text { Phenotypic } \\
\text { variance } \\
\text { range (\%) }\end{array}$ & $\begin{array}{l}\text { Additive effect } \\
\text { range }(\mathrm{a} 0)\end{array}$ & $\begin{array}{l}\text { QTLs } \\
\text { identified }\end{array}$ & $\begin{array}{l}\text { LOD value } \\
\text { range }\end{array}$ & $\begin{array}{l}\text { Phenotypic } \\
\text { variance } \\
\text { range (\%) }\end{array}$ & $\begin{array}{l}\text { Additive effect } \\
\text { range }(\mathrm{a} 0)\end{array}$ \\
\hline Oleic acid (C18:1) & 8 & $2.50-33.09$ & $1.59-27.54$ & 5.04 to $(-) 12.758$ & 9 & $2.52-15.44$ & $3.63-28.98$ & 4.095 to (-) 2.12 \\
\hline Linoleic acid (C18:2) & 7 & $2.54-32.41$ & $1.46-28.22$ & 10.878 to (-) 2.717 & 9 & $3.72-15.8$ & $3.91-25.49$ & 1.873 to $(-) 3.20$ \\
\hline $\begin{array}{l}\text { Oleic/linoleic } \\
\text { acid ratio (OLR) }\end{array}$ & 6 & 2.53-118.87 & $1.04-42.33$ & 1.13 to $(-) 12.29$ & 5 & $3.78-9.82$ & $5.70-14.90$ & 0.82 to $(-) 0.221$ \\
\hline Oil content (OC) & 6 & $2.85-9.27$ & $3.07-10.23$ & 3.53 to $(-) 4.44$ & 9 & $2.53-8.00$ & $3.93-14.07$ & 0.858 to (-) 0.601 \\
\hline
\end{tabular}

Two consistent QTLs namely IPAHM372-ahFAD2A and GM1840-ahFAD2B in the S-population (Additional file 5) and two consistent QTLs namely GNB377-ahFAD2A and GM2690-1-IPAHM606 were identified for oleic acid (C18:1) in T-population (Additional file 6).

For linoleic acid (C18:2), a total of seven and nine M-QTLs were detected in the S- and the T-population with PVE up to $28.22 \%$ and $25.49 \%$, respectively (Table 2). The ahFAD2A (7.97\% and 5.76\%) and ahFAD2B (28.22\% and $22.96 \%$ ) genes showed consistent high contribution in both years in the S-population and, in similar way, ahFAD2A (25.49\% and $11.98 \%)$ contributed in the T-population. In contrast to oleic acid (C18:1), the contributing alleles of $a h F A D 2 A$ and $a h F A D 2 B$ genes

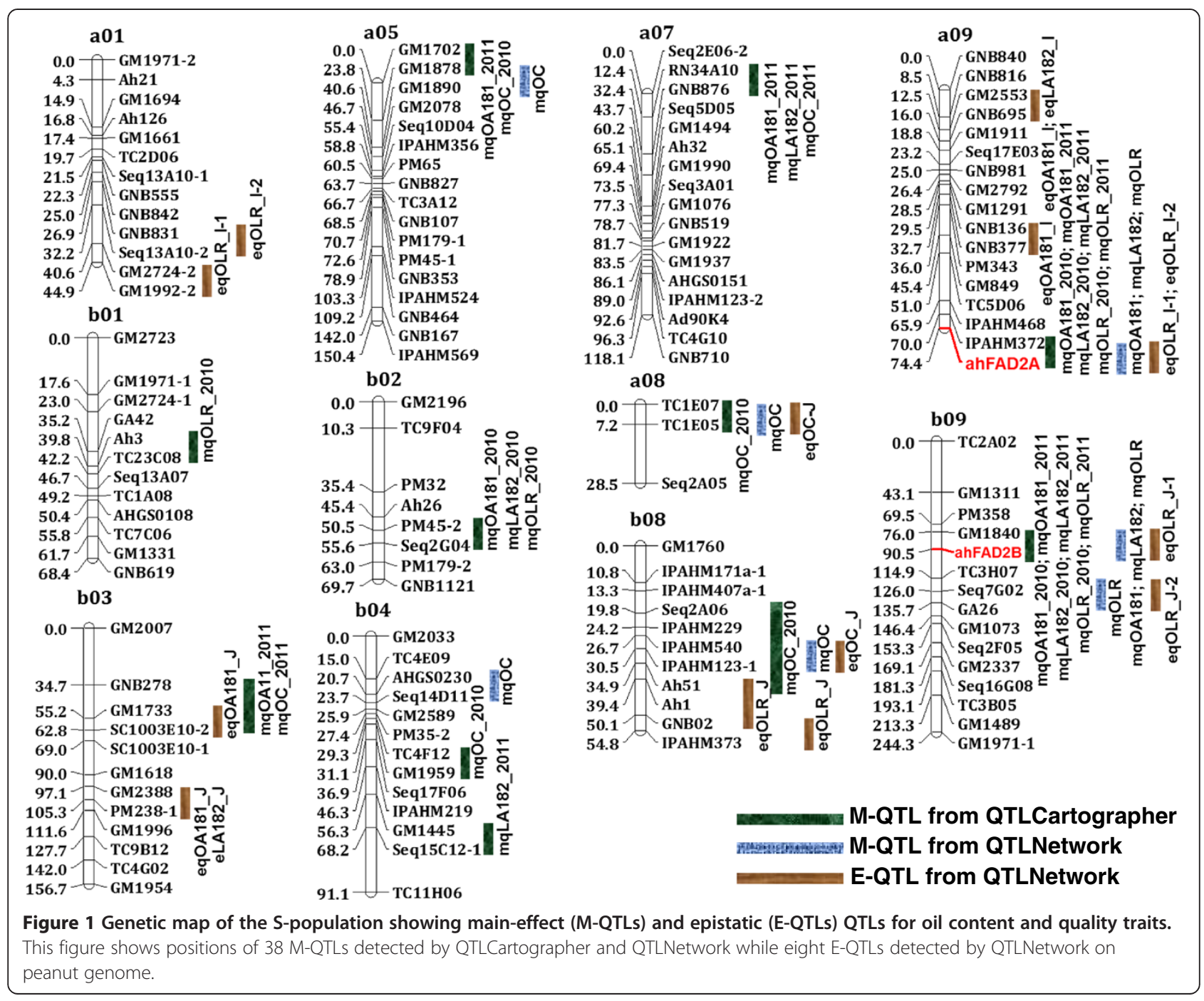




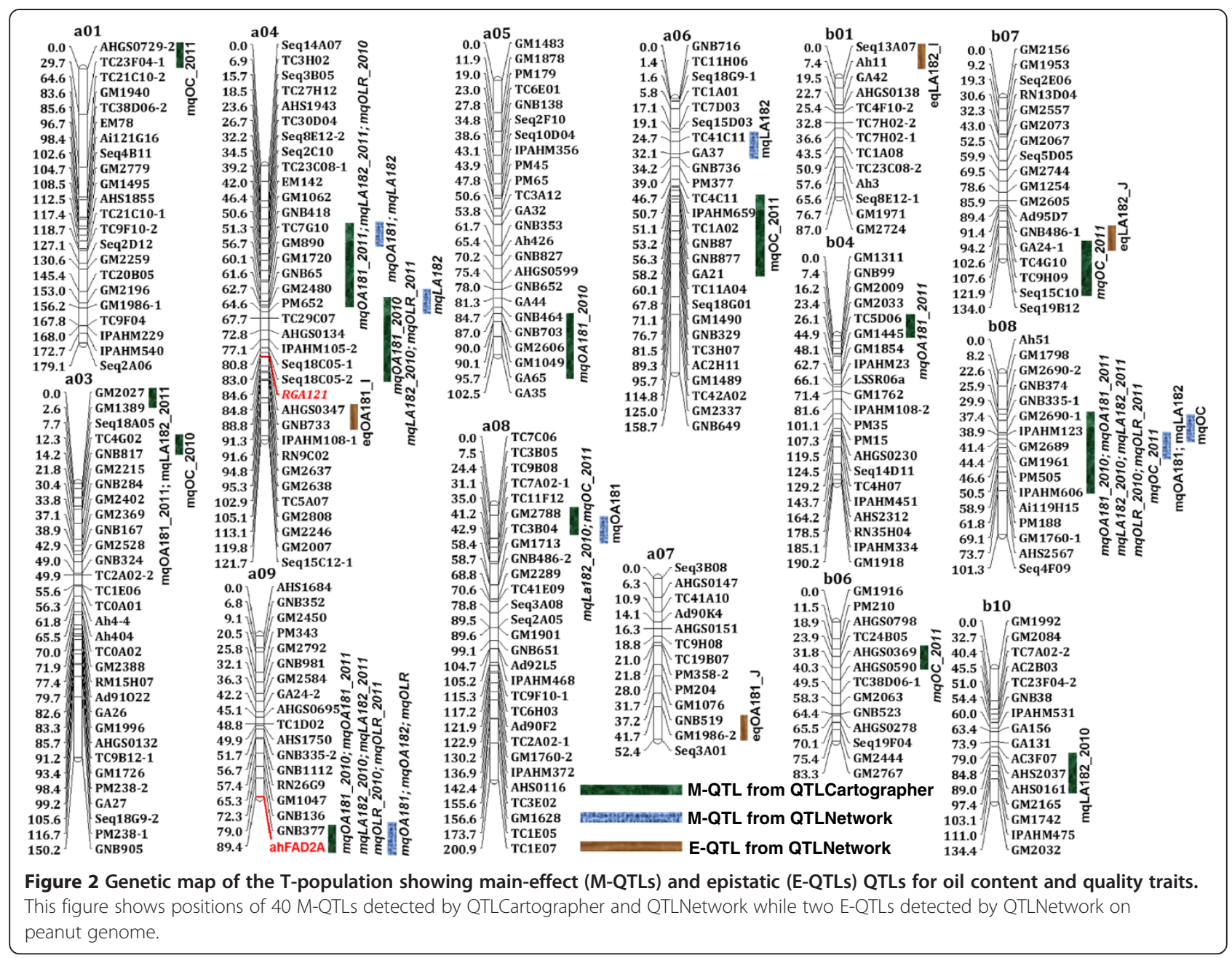

for high linoleic acid (C18:2) came from the parent 'NC94022' of the S-population while contributing allele for $a h F A D 2 A$ came from the parent 'GT-C20' of the T-population. In terms of consistency of the QTLs, two consistent QTL regions namely IPAHM372-ahFAD2A and GM1840-ahFAD2B were identified for linoleic acid (C18:2) in the S-population (Additional file 5). Similarly in the T-population, two consistent QTLs namely GNB377ahFAD2A and GM2690-1-IPAHM606 were identified for linoleic acid (C18:2) (Additional file 6).

A total of six and five M-QTLs were detected for $\mathrm{O} / \mathrm{L}$ ratio in the $\mathrm{S}$ - and the T-population with PVE up to $42.33 \%$ and $14.90 \%$, respectively (Table 2 ). Similar to oleic acid (C18:1) and linoleic acid (C18:2), ahFAD2A (4.16\% and $3.42 \%)$ and $a h F A D 2 B(39.71 \%$ and $42.33 \%)$ genes showed consistent high contribution in both the years in the S-population while ahFAD2A $(14.90 \%$ and $6.08 \%)$ showed in the T-population. The results for $\mathrm{O} / \mathrm{L}$ ratio were similar to oleic acid (C18:1) and in contrast to linoleic acid (C18:2). The mutant alleles of ahFAD2A and $a h F A D 2 B$ genes present in 'SunOleic 97R' parent of the S-population contributed for high oleic acid (C18:1) while mutant allele of $a h F A D 2 A$ gene present in 'Tifrunner' contributed for $\mathrm{O} / \mathrm{L}$ ratio in the $\mathrm{T}$-population. In terms of consistency of the QTLs for $\mathrm{O} / \mathrm{L}$ ratio, only two consistent QTLs namely IPAHM372-ahFAD2A and GM1840-ahFAD2B were identified in the S-population (Additional file 5). The above two consistent QTLs harboured well known ahFAD2A and $a h F A D 2 B$ genes on LG a09 and b09, respectively (Figure 1). In the T-population, one consistent QTL namely GNB377-ahFAD2A could be identified for $\mathrm{O} / \mathrm{L}$ ratio (Additional file 6).

The distribution of total oil content in the S- and the T-population was normal (Figure 3). For oil content, a total of six and seven M-QTLs were identified in the Sand the T-population with PVE up to $10.23 \%$ and $14.07 \%$, respectively (Table 2 ). It was interesting to note that no consistent QTL could be identified for oil content in either of the populations (Additional files 5 and 6).

In addition to the identification of consistent QTLs for a single trait on a particular genomic region, such QTLs for multiple traits were also found on the same genomic 


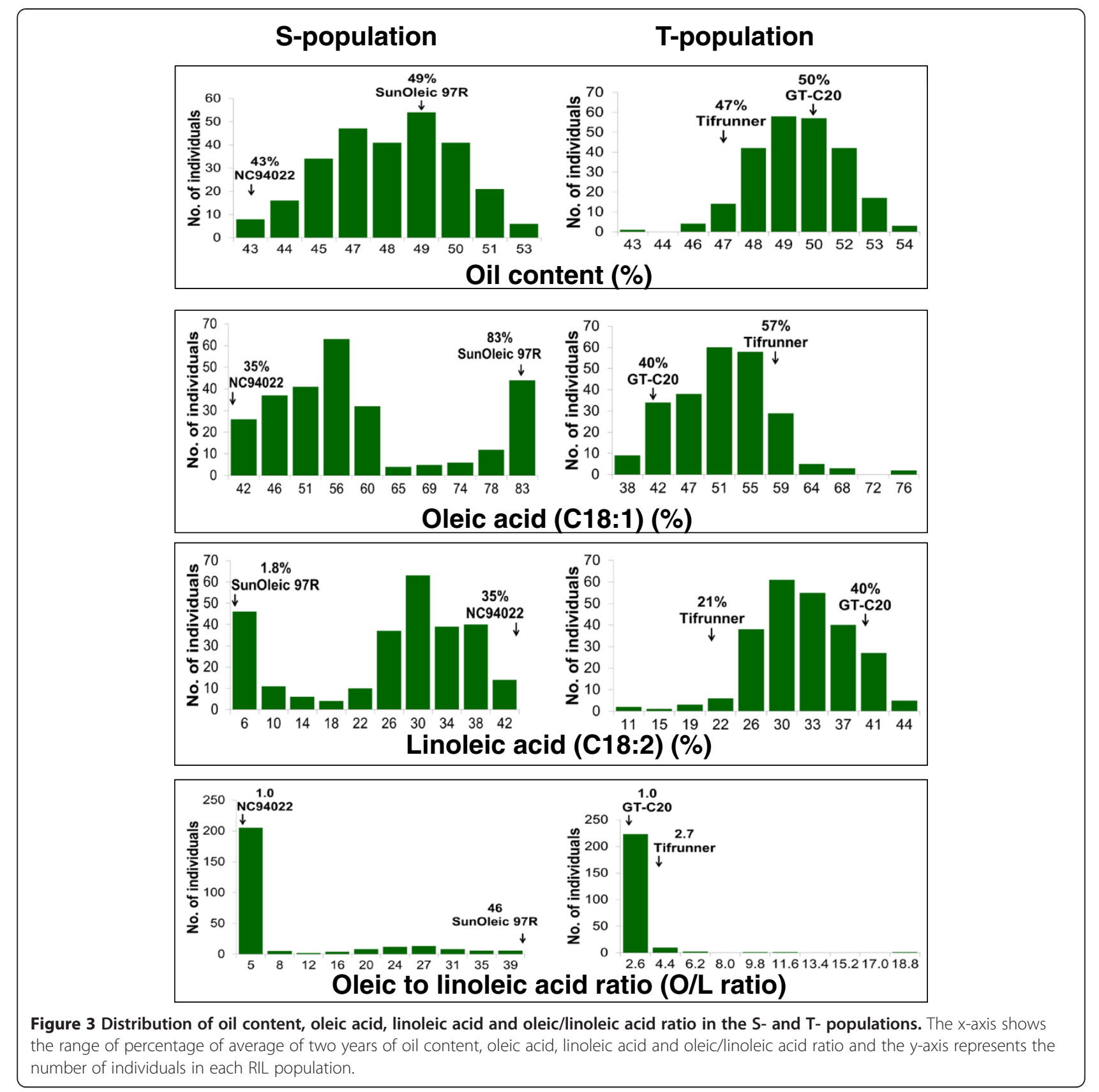

regions. Interestingly, two QTLs (IPAHM372-ahFAD2A and GM1840-ahFAD2B) on a09 and b09 in the S-population and one QTL (GNB377-ahFAD2A) on a09 had two consistent QTLs each for oleic acid (C18:1), linoleic acid (C18:2) and $\mathrm{O} / \mathrm{L}$ ratio (Table 2, Additional files 5 and 6, Figures 1 and 2). In addition to these QTLs, the other QTLs which were found to control more than one trait are GM1702-GM1878 (oleic acid and oil content) and RN34A10-GNB876 (oleic acid, linoleic acid and oil content) in the S-population (Additional file 5) while GM2690-1-IPAHM606 (oleic acid, linoleic acid, O/L ratio and oil content), PM652Seq18C05-2 (oleic acid, linoleic acid and O/L ratio), TC7G10-PM652 (oleic acid, linoleic acid and O/L ratio), and GM2788-TC3B04 (linoleic acid and oil content) in the T-population (Additional file 6).

Identification of main-effect QTLs (M-QTLs) by QTLNetwork

Analysis using QTLNetwork resulted in identification of a total of 11 M-QTLs each for the S- and T-population for all the four oil traits and PVE ranged from 0.25 to $25.52 \%$ 
and 0.46 to $29.13 \%$, respectively (Table 3 , Additional files 7 and 8, Figures 1 and 2). Of the total QTLs identified in both the populations, four QTLs in the S-population and two QTLs in the T-population had major phenotypic effect (>10\% PVE) (Additional files 7 and 8 ).

For oleic acid (C18:1), two M-QTLs in the S-population while four M-QTLs in the T-population were identified with PVE up to $14.18 \%$ and $29.13 \%$, respectively. Only one major M-QTL each could be detected for oleic acid (C18:1) in the S-population (GM1840-ahFAD2B with $14.18 \%$ PVE) and T-population (GNB377-ahFAD2A with 29.13\% PVE). Additive effect for ahFAD2A and $a h F A D 2 B$ genes indicated that the contribution for high oleic acid (C18:1) came from the 'SunOleic 97R' parent in the $\mathrm{S}$-population and for ahFAD2A gene from 'Tifrunner' in the T-population. Similarly, two and five M-QTLs were detected for linoleic acid (C18:2) in the S- and T-population with PVE up to $13.83 \%$ and $26.64 \%$, respectively. Only one major M-QTL could be detected for linoleic acid (C18:2) in the S-population (GM1840ahFAD2B with $13.83 \%$ PVE) and T-population (GNB377ahFAD2A with $26.64 \%$ PVE). Additive effect for ahFAD2A and $a h F A D 2 B$ indicated that the contribution for high linoleic acid (C18:2) came from the parent 'NC94022' in the S-population and for ahFAD2A gene from 'GT-C20' in the T-population. Three M-QTLs with PVE up to $10.82 \%$ in the S-population and one M-QTL with PVE up to $5.19 \%$ were detected for $\mathrm{O} / \mathrm{L}$ ratio. Only one major M-QTL could be detected for O/L ratio in the S-population (GM1840-ahFAD2B with 10.82\% PVE) while no major M-QTL was detected in the T-population (Additional files 7 and 8). For oil content, a total of four M-QTLs in the S-population and one M-QTL in the T-population were identified with PVE up to $25.52 \%$ and $6.7 \%$, respectively. Only one major M-QTL could be detected for oil content in the S-population (GM1878-GM1890 with 25.52\% PVE) while there was no major M-QTL identified in the T-population. For this major QTL (25.52\% PVE), the allele from the parent 'SunOleic 97R' contributed towards high oil content while allele from the parent 'NC94022' contributed towards low oil content. The same QTL was also detected by QTLCartographer.

\section{Identification of epistatic effect QTLs (E-QTLs) by QTLNetwork}

QTL analysis using QTLNetwork for oil content and quality traits resulted in identification of ten E-QTLs (eight in the S-population and two in the T-population) with only two-locus interactions (Figure 4, Table 4, Additional file 9). The PVE for E-QTLs detected in the $\mathrm{S}$-population ranged from 0.13 to $3.1 \%$ and additive effect due to interaction of both the loci varied from 3.08 to -1.06. Similarly, the PVE\% for E-QTLs detected in the T-population ranged from 1.69 to $2.9 \%$ and additive effect due to interaction of both the loci varied from 1.12 to $1.17 \%$. FAD2 genes/alleles were found to be involved in two out of the ten interactions and both interactions involved linoleic acid (C18:2) in the S-population. The other QTLs which had appeared in more than one interaction include GM2553-GNB695 and GM2388-PM238-1 (Additional file 9). Three two-locus interactions were identified for oleic acid with the PVE ranging from 1.6 to $2.89 \%$ i.e., two in the S-population and one in the T-population. One two-locus interaction was identified in each population for linoleic acid (C18:2) with PVE ranging from 2.82 to $2.90 \%$ (Table 4, Additional file 9). No E-QTL could be identified for $\mathrm{O} / \mathrm{L}$ ratio and oil content in the $\mathrm{T}$-population, while four E-QTLs could be identified for O/L ratio (PVE up to $3.1 \%$ ) and a single E-QTL for oil content with PVE of $0.88 \%$.

\section{Discussion}

Trait importance and development of RIL mapping populations

Oleic acid (C18:1) is a monounsaturated fatty acid while linoleic acid (C18:2) is a polyunsaturated fatty acid and both together make upto $80 \%$ of the oil composition. The desirability of high oleic acid (C18:1) lies in its good property of providing longer shelf life due to ten-fold higher anti-oxidative stability compared to linoleic acid (C18:2). Besides longer shelf life, it also plays an important role to human health by decreasing blood LDL levels, suppressing tumorigenesis and ameliorating inflammatory diseases $[8,9,22]$. Enhancing or lowering oil content is an important breeding objective in majority of

Table 3 Summary of main-effect QTLs (M-QTLs) identified by QTLNetwork in the S-population and the T-population

\begin{tabular}{|c|c|c|c|c|c|c|c|c|}
\hline \multirow[t]{2}{*}{ Traits } & \multicolumn{4}{|c|}{ S-population } & \multicolumn{4}{|c|}{ T-population } \\
\hline & $\begin{array}{l}\text { QTLs } \\
\text { identified }\end{array}$ & $\begin{array}{l}\text { P-value } \\
\text { range }\end{array}$ & $\begin{array}{l}\text { Phenotypic } \\
\text { variance } \\
\text { range }(\%)\end{array}$ & $\begin{array}{l}\text { Additive effect } \\
\text { range }(\mathrm{a} 0)\end{array}$ & $\begin{array}{l}\text { QTLs } \\
\text { identified }\end{array}$ & $\begin{array}{l}\text { P-value } \\
\text { range }\end{array}$ & $\begin{array}{l}\text { Phenotypic } \\
\text { variance } \\
\text { range (\%) }\end{array}$ & $\begin{array}{l}\text { Additive effect } \\
\text { range }(\mathrm{a} 0)\end{array}$ \\
\hline Oleic acid (C18:1) & 2 & 0 & $8.72-14.18$ & $(-) 4.44$ to $(-) 5.91$ & 4 & 0.00 & $0.46-29.13$ & 4.49 to $(-) 1.63$ \\
\hline Linoleic acid (C18:2) & 2 & 0.00 & 8.36-13.83 & 3.42 to 4.91 & 5 & $0.00-1.6 \times E-5$ & $0.86-26.64$ & 1.02 to (-) 3.70 \\
\hline $\begin{array}{l}\text { Oleic/linoleic } \\
\text { acid ratio (OLR) }\end{array}$ & 3 & 0.0 to $3.1 \times E-5$ & $0.25-10.82$ & 1.47 to $(-) 3.90$ & 1 & 0.00 & 5.19 & 0.422 \\
\hline Oil content (OC) & 4 & 0.00 & $4.79-25.52$ & 0.533 to $(-) 1.465$ & 1 & 0.00 & 6.70 & 0.546 \\
\hline
\end{tabular}




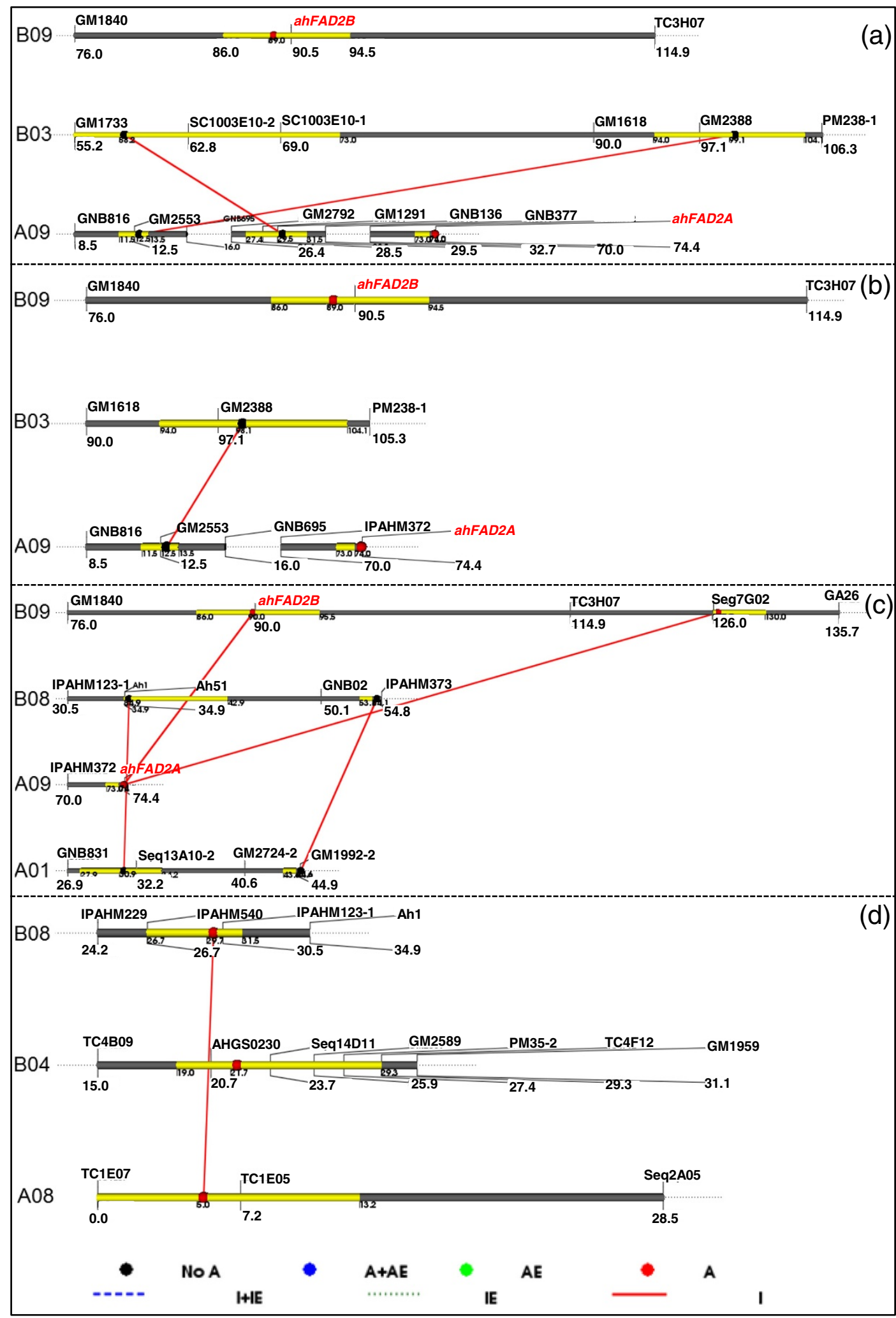

Figure 4 (See legend on next page.) 
(See figure on previous page.)

Figure 4 Epistatic interaction identified by QTL Network for oil quality traits. Figure shows epistatic interaction for (a) oil content, (b) oleic acid, (c) linoleic acid, and (d) oleic/linoleic (O/L) ratio. The black ball represents epistatic QTLs without individual effect; the blue ball represents additive $\times$ (additive $\times$ environment) interaction; the red ball indicates epistatic QTLs with direct individual effect while interacting loci are shown by red colored bars.

the breeding programs of the world. In this context, the present study was done to identify QTLs/linked markers associated with oil content to deploy them after validation in developing improved genotypes with desired level of oil content. In addition to the oil content, improving the peanut oil quality is another major breeding objective after pod yield and oil content. Although genebased markers are available for both the mutant FAD2 genes ( $a h F A D 2 A$ and $a h F A D 2 B$ ), their location on the peanut genome and their relative contribution towards oil quality are not known. Therefore, two RIL mapping populations were developed and used in this study to generate information to meet the research needs. The S-population segregated for both the FAD2 genes (ahFAD2A and ahFAD2B) while the T-population segregated for only one FAD2 gene (ahFAD2A).

It is well known that small population size (100-200 lines) has adverse effect on the accuracy in identifying QTL positions and estimating QTL effects [23,24]. Two large RIL populations with 352 (S-population) and 248 (T-population) individuals were developed and used to phenotype for oil content and quality traits in two successive years (2010 and 2011). These two populations were then used for locating the position of QTLs and $F A D 2$ genes on the peanut genome, and identification of associated markers for oil content and quality traits.

\section{Development of improved genetic maps}

Both genetic maps were enriched with additional polymorphic markers i.e., from 172 loci to 206 loci for the S-population and from 236 loci to 378 loci for the T-population in comparison with the earlier maps by Qin et al. [21]. In both the populations, comparatively higher number of loci could be mapped in the A subgenome (110 loci in the S-population and 224 loci in the T-population) than the B sub-genome (94 loci in the Spopulation and 153 loci in the T-population). The genome coverage of T-population was higher $(2487.4 \mathrm{cM})$ than the $\mathrm{S}$-population $(1780.6 \mathrm{cM})$. The map features of these two populations indicated that the $\mathrm{A}$ sub-genome is more diverse than the B sub-genome.

So far only seven genetic maps based on RIL populations have been reported in peanut. Individual genetic maps were constructed for the $\mathrm{S}$ - and T-population earlier with 172 (920.7 cM) and $236(1,213.4 \mathrm{cM})$ marker loci, respectively [21]. The other five genetic maps based on RILs included TAG $24 \times$ ICGV 86031 (291 loci, 1,785.4 cM, [25,26]), ICGS $76 \times$ CSMG 84-1 (119, loci, 2,208.2 cM, [27]), ICGS $44 \times$ ICGS 76 (82 loci, $831.4 \mathrm{cM}$, [27]), TAG $24 \times$ GPBD 4 (188 SSR loci, 1,922.4 cM, [28] ) and TG $26 \times$ GPBD 4 (181 SSR loci, 1,963 cM, [28]). Thus, the current map of the T-population possesses the highest number (378) of marker loci among all the genetic maps constructed so far using RIL population.

\section{Identification of QTLs for oil content and quality traits}

Total PVE of a complex trait results from the presence of multiple QTLs as well as their interactions (QTL to QTL and QTL to environment). Hence, in the present study two genetic softwares were used for identification of M-QTLs (QTLCartographer and QTLNetwork) and E-QTLs (QTLNetwork). QTL analysis resulted in identification of a total of 38 (27 by QTLCartographer and 11 by QTLNetwork) M-QTLs in the S-population and 40 (29 by QTLCartographer and 11 by QTLNetwork) M-QTLs in the T-population. The PVE ranged from 0.24 to

Table 4 Summary of epistatic QTLs (E-QTLs) identified by QTLNetwork in the S-population and the T-population

\begin{tabular}{|c|c|c|c|c|c|}
\hline Traits & QTLs identified & PVE range (\%) & AA range & SE range & $\mathrm{P}$-value range \\
\hline \multicolumn{6}{|l|}{ S-population } \\
\hline Oleic acid (C18:1) & 2 & $1.6-2.83$ & 3.08 to $(-) 2.58$ & $0.510-0.514$ & 0.00 \\
\hline Linoleic acid (C18:2) & 1 & 2.82 & -2.0905 & 0.4311 & $1 \times E-6$ \\
\hline Oleic/linoleic acid ratio (OLR) & 4 & $0.13-3.1$ & 2.11 to $(-) 1.43$ & $0.378-0.399$ & 0.00 to $3 \times E-4$ \\
\hline Oil content (OC) & 1 & 0.88 & -0.2623 & 0.085 & 0.002041 \\
\hline \multicolumn{6}{|l|}{ T-population } \\
\hline Oleic acid (C18:1) & 1 & 1.69 & 1.1219 & 0.2896 & $1 \times E-4$ \\
\hline Linoleic acid (C18:2) & 1 & 2.9 & 1.1695 & 0.2292 & 0 \\
\hline
\end{tabular}

AA: The estimated additive effect; SE: The standard error of estimated or predicted QTL effect and P-value. 
$42.33 \%$ in the S-population and from 0.46 to $28.98 \%$ in the T-population. In case of E-QTLs, ten E-QTLs (eight in the S-population and two in the T-population) were detected with PVE ranging from $0.13-3.1 \%$ and additive effect ranging from 3.08 to -1.06 . It was interesting to note that $F A D 2$ genes/alleles were found to be involved in two out of ten interactions and both involved linoleic acid in the S-population.

It was interesting that there was three-fold difference in detection of QTLs by both the software used in this study. The difference in number of QTLs detected is due to the variation in the algorithm of the software. The CIM of the QTLCartographer fits parameter to target QTL in one interval and simultaneously fits partial regression coefficients for background markers in order to account variance due to non-target QTL. It allows this software to consider various gene actions (additive and dominance) and QTL by environment interactions and close linkage. On the other hand, the CIM of the QTLNetwork is based on the mixed-model method.

As expected FAD2 genes controlled three oil quality traits (oleic acid, linoleic acid and $\mathrm{O} / \mathrm{L}$ ratio) but had no effect on oil content. Results clearly showed that the contribution of $a h F A D 2 B$ to PVE for oleic acid (C18:1), linoleic acid (C18:2) and O/L ratio were always higher than the contribution of the $a h F A D 2 A$ gene. The QTL 'TC6H03-TC11A04' had been reported earlier for significant contribution to oleic acid (9.70\% PVE), linoleic acid (9.00\% PVE) and O/L ratio (6.80\% PVE) [29]. The low PVE reported by Sarvamangala et al. [29] may have been due to the low level of divergence among the parental genotypes for oil quality traits and the lack of sufficient marker loci representing the peanut genome. More recently, 25 marker-trait associations (MTAs) for oil content (5.84-40.37\% PV), two MTAs for oleic acid (16.42\% PV) and 22 MTAs for O/L ratio (13.67-47.45\% PV) were identified in a comprehensive genome-wide association studies (GWAS) [30]. Of the four associated markers TC4G02, Seq7G02, TC11A04 and Seq3B05 for oil content [30], the marker TC11A04 was also found associated with oil quality traits in the present study as well as the previous study [29].

No detailed studies on FAD2 genes towards their role in controlling oil quality and content have been conducted in peanut and hence no literature is available to draw comparisons. Nevertheless, similar studies were conducted in other crops such as rapeseed (Brassica napus) [31] and soybean (Glycine max) [32]. Similar to peanut, two FAD2 genes are reported to be present in rapeseed (B. napus) on two different genomes i.e., the A-genome and the $\mathrm{C}$-genome. However in soybean, two oleate desaturase genes $(F A D 2-1 A$ and $F A D 2-1 B)$ and three linoleate desaturase genes ( $F A D 3 A, F A D 3 B$ and $F A D 3 C$ ) were identified and unambiguous chromosomal positions were assigned [32]. It was clearly indicated in rapeseed that the QTL for oleic acid had a negative effect on linoleic acid [31] which is also been found in the present study. We have clearly observed that ahFAD2A and $a h F A D 2 B$ mutant alleles increased the quantity of oleic acid (C18:1) and decreased the production of linoleic acid (C18:2) which resulted in high $\mathrm{O} / \mathrm{L}$ ratio. Thus, these studies provide genetic evidence that the gene products of these FAD2 alleles catalyze the conversion of oleic acid (C18:1) to linoleic acid (C18:2).

\section{Consistent M-QTLs for improving oil content and quality traits}

Realizing the practical importance of consistent QTLs over seasons, $a h F A D 2 A$ and $a h F A D 2 B$ genes showed a consistent high contribution in the $S$-population and ahFAD $2 A$ in the T-population for oleic acid (C18:1), linoleic acid $(\mathrm{C} 18: 2)$ and $\mathrm{O} / \mathrm{L}$ ratio. These two consistent QTLs namely IPAHM372-ahFAD2A and GM1840-ahFAD2B in the S-population while GNB377-ahFAD2A in the T-population controlled three oil quality traits namely oleic acid (C18:1), linoleic acid (C18:2), and $\mathrm{O} / \mathrm{L}$ ratio. It was interesting to note that the additive effect for $a h F A D 2 A$ and $a h F A D 2 B$ indicated that the contribution for high oleic acid and $\mathrm{O} / \mathrm{L}$ ratio came from the 'SunOleic 97R' parent in the S-population while for ahFAD2A gene from 'Tifrunner' in the T-population. In contrast to oleic acid (C18:1), additive effect for $a h F A D 2 A$ and $a h F A D 2 B$ indicated that the contribution for high linoleic acid (C18:2) came from the 'NC94022' parent in the S-population and for ahFAD2A gene from 'GT-C20' in the T-population.

Among consistent QTLs, two consistent QTL regions were identified, each for oleic acid (C18:1) and linoleic acid (C18:2) in both the populations. In case of O/L ratio, two consistent QTL regions in the S-population and one consistent QTL region were identified in the T-population. For oil content, no consistent QTL could be identified in either of the populations which shows the complexity of the trait and extent of environmental influence. In addition to the above consistent QTLs, the two other QTLs controlling more than one trait were also identified in the $\mathrm{S}$-population and four in the T-population. It is noted that one RGA-121 marker was mapped on a04 with linkage to oil quality traits (Figure 2, Additional file 6) in the T-population, was also reported to be linked to disease resistance QTLs [33]. The consistent QTLs identified in this study provided confidence on these QTLs and their role towards controlling these traits. Such consistent QTLs have earlier been identified for foliar fungal diseases and were also successfully deployed in genomics-assisted breeding for improving rust resistance [34]. Therefore, the markers underlying these consistent QTLs are of great importance and 
may be deployed after validation in improving oil content and oil quality traits through genomics-assisted breeding.

\section{Relative contribution of mutant alleles towards oil quality traits}

The current general understanding is that genotypes possessing both the mutant alleles (ahFAD2A and ahFAD2B) will produce higher oleic acid (C18:1) and reduced linoleic acid (C18:2). The mutant allele ahFAD2A is widely available in the U.S. peanut germplasm collection and in elite genotypes but mutant allele ahFAD2B is not available in the U.S. germplasm collection [35]. The mutant allele ahFAD2B is present in selected genotypes such as SunOleic $95 \mathrm{R}$, SunOleic $97 \mathrm{R}$, most of which trace their pedigrees to F435 (except Flavorunner 458). There are no systematic studies on estimating phenotypic contribution of QTLs and these two mutant alleles towards oil quality traits but there are surveys and studies recently on FAD2 genes effect on fatty acid profiles and oil content [36-39]. This fact also raises a question that what makes the two mutant alleles to produce more oleic acid (and less linoleic acid) when both mutant alleles are present together and less oleic acid (and high linoleic acid) when either of the mutant alleles are present separately (Table 5). Further, the involvement of other factors in influencing the production of oleic acid should be very possible. Therefore, more information on this aspect needs to be generated for improving further understanding of the genetic control and pathway functionality for fatty acid synthesis in peanut.

\section{Conclusion}

Oil content and quality traits have high impact on peanut markets due to profitability and consumers preference for several health benefits. The FAD2 genes are known to control some of these traits and their position on the peanut genome and their contributions towards total phenotypic variance for these quality traits were unknown. Two RIL mapping populations were used for identification of QTL positions and estimating QTL effects.
This study reports the development of two improved genetic maps and identification of 78 M-QTLs and $10 \mathrm{E}-\mathrm{QTLS}$ for oil content and three oil quality traits (oleic acid, linoleic acid and $\mathrm{O} / \mathrm{L}$ ratio). The ahFAD2A and ahFAD2B genes were mapped to the homeologous linkage groups of A (a09) and B sub-genome (b09). The results indicated that the contribution of both the mutant alleles together was much higher than the cumulative individual effect of $F A D 2$ genes. Further, the QTL analysis always detected higher PVE for ahFAD2B for oleic acid (C18:1), linoleic acid (C18:2) and O/ $\mathrm{L}$ ratio than the $a h F A D 2 A$ genes. This study not only estimated phenotypic effect of both the FAD2 genes for (C18:1), linoleic acid (C18:2) and $\mathrm{O} / \mathrm{L}$ ratio but also identified additional QTLs controlling these quality traits. By increasing the proportion of oleic acid in peanut oil, at the expense of linoleic acid, the oxidative stability can be increased in addition to the health benefits. The information generated through this study should be very useful for marker-assisted development of improved peanut varieties with desired oil content and quality traits.

\section{Methods}

\section{Development of mapping populations}

Two recombinant inbred line (RIL) populations derived from the crosses 'SunOleic 97R' [19] × 'NC94022' (S-population), and 'Tifrunner' [40] × 'GT-C20' (T-population) were developed following single seed decent (SSD) method at Crop Protection and Management Research Unit, USDA-ARS, Tifton, USA. The genotype 'SunOleic 97R' was developed from the cross 'SunOleic 95R' $\times$ 'Sunrunner', and 'NC94022' is a breeding line derived from the cross 'N91026E' × 'PI 576638'. The female parent of the T-population, 'Tifrunner', is a runner market-type cultivar and the male parent, 'GT-C20', is a Spanish-type breeding line. The S-population and the T-population had 352 and 248 individuals, respectively and were used for multiseason phenotyping for oil content and three oil quality (oleic acid, linoleic acid and $\mathrm{O} / \mathrm{L}$ ratio) traits.

\section{Phenotyping of mapping populations}

Full sets of the S- and T-population along with parental genotypes were grown in three replications during 2010

Table 5 Phenotypic value in percentage of the oil quality traits in RILs by genotypes of ahFAD2A and ahFAD2B genes in the S-population and the T-population

\begin{tabular}{|c|c|c|c|c|c|c|}
\hline \multirow[t]{2}{*}{ Quality traits } & \multicolumn{4}{|c|}{ S-Population } & \multicolumn{2}{|c|}{ T-population } \\
\hline & AABB (66) & AAbb (51) & aaBB (65) & aabb (60) & AABB (92) & aaBB (130) \\
\hline Oleic acid (C18:1) & 46.52 & 57.03 & 55.58 & 70.23 & 44.2 & 52.56 \\
\hline Linoleic acid (C18:2) & 32.50 & 23.79 & 25.03 & 12.72 & 34.2 & 27.44 \\
\hline Oleic/linoleic acid ratio (OLR) & 2.17 & 5.09 & 4.50 & 17.68 & 1.35 & 2.22 \\
\hline
\end{tabular}

AA: wild A sub-genome allele for ahFAD2A gene in homozygous condition, aa: mutant A sub-genome allele for ahFAD2A gene in homozygous condition, Aa: ahFAD2A gene in heterozygous condition in A sub-genome, BB: wild B sub-genome allele for ahFAD2B gene in homozygous condition, bb: mutant $B$ sub-genome allele for ahFAD2B gene in homozygous condition, Bb: ahFAD2B gene in heterozygous condition in $B$ sub-genome. The number in parentheses is the number of RILs with that specific genotype. 
( $\mathrm{F}_{7}$ generation) and $2011\left(\mathrm{~F}_{8}\right.$ generation) at the Bellflower Farm, Tifton, GA. Recommended agronomic and management practices were followed to grow a healthy crop. Harvested pods from all the replications of RIL lines were properly dried, packed and sent to USDA-ARS, Griffin (USA) for chemical analysis of oil content, oleic acid (C18:1) and linoleic acid (C18:2). The O/L ratio was calculated using the values of oleic acid (C18:1) and linoleic acid (C18:2).

Oil content: A Maran Pulse nuclear magnetic resonance (NMR, Resonance Instruments, Whitney Oxfordshire, UK) was used to determine the oil content in percentage. The NMR calculated oil\% and $\mathrm{H}_{2} \mathrm{O} \%$ in the sample. Total 5-10 g of whole mature seeds were weighed and analyzed for each of two subsamples per entry. Oil percentage was calculated and determined on a basis of zero percent water content in seed by using the formula $\left[\right.$ oil $\left.\% \times 100 /\left(100-\mathrm{H}_{2} \mathrm{O} \% \times 100\right)\right]$.

Oleic (C18:1) and linoleic (C18:2) acids: Three to five seeds were ground to a fine powder in a coffee bean grinder. Approximately $150 \mathrm{mg}$ of ground powder was transferred into a $16 \times 100 \mathrm{~mm}$ disposable test tube, and $5.0 \mathrm{ml}$ of n-heptane (Fisher Scientific) was added to extract the oil. For conversion of fatty acids to methyl esters, $500 \mu \mathrm{l}$ of $0.5 \mathrm{~N}$ sodium methoxide $\left(\mathrm{NaOCH}_{3}\right)$ in methanol solution was added to the test tube and mixed with the sample. After 2 hours, $7.0 \mathrm{ml}$ of distilled water was added to separate the organic layer from the aqueous layer and seed residue ( $45 \mathrm{~min})$. An aliquot of the organic layer $(1.5 \mathrm{ml})$ containing the methyl esters was transferred to a $2.0 \mathrm{ml}$ autosampler vial for GC analysis. Fatty acid composition was determined using an Agilent 7890A gas chromatograph (GC) equipped with a flame ionization detector (FID) and an autosampler. A fatty acid methyl ester (FAME) standard mix RM-3 (purchased from Sigma) was used to establish peak retention times. Peak separation was performed on a DB-225 capillary column $(15 \mathrm{~m} \times 0.25 \mathrm{~mm}$ i.e. with a $0.25 \mu \mathrm{m}$ film) from Agilent Technologies. The carrier gas was helium set to a flow rate of $\sim 1.0 \mathrm{ml} / \mathrm{min}$. One $\mu \mathrm{l}$ of sample was injected at a 60:1 split ratio onto the column maintained isothermally at $210^{\circ} \mathrm{C}$. The inlet and detector were set to $280^{\circ} \mathrm{C}$ to $300^{\circ} \mathrm{C}$, respectively. Total run time for each sample was 12 minutes. Oleic (C18:1) and linoleic (C18:2) acid composition was determined by identifying and calculating relative peak areas.

\section{DNA extraction and genotyping of genetic material}

DNA was extracted from fresh leaves of the parental genotypes and the RILs as described in Qin et al. [21]. After assessing the quality and quantity of isolated genomic DNA in Nano Drop-1000 spectrophotometer, PCR reactions were carried out in $15 \mu \mathrm{l}$ reaction volumes using thermal cycler (PTC-225 DNA Engine Tetrad Peltier, MJ
Research, USA and DNA Engine Tetrad 2 Peltier, BioRad Laboratories, USA). The master mix was prepared using $0.5 \mu \mathrm{M}$ of each primer, $25 \mathrm{ng}$ genomic DNA, 10X PCR buffer, $1.5 \mathrm{mM} \mathrm{MgCl}, 0.2 \mathrm{mM}$ of dNTPs and $0.5 \mathrm{U}$ of Taq polymerase. PCR profiles and band scoring was done as explained in Qin et al. [21]. A total of 230 and 402 polymorphic markers were identified for the S- and the T-population, respectively. Genotyping data for 215 SSR loci in the S-population and 390 SSR loci in the T-population were generated on the full sets of RILs. The information on source of the markers and names used in Qin et al. [21] and present study has been provided in Additional file 10.

\section{Construction of improved genetic maps}

Genotyping data obtained for all the polymorphic marker loci were scored as "a" and "b" to use in the construction of an improved genetic map using JoinMap version 4. Genotyping data were first analysed for segregation distortion for each marker loci to calculate chi-square values using a "locus genotype frequency" function against the expected 1:1 ratio. Due to segregation distortion for some SSR loci, initially a framework genetic map was prepared with normally segregating markers at LOD of 4.0 with a minimum recombination threshold of $40 \%$. Marker loci were placed into respective linkage groups (LG) using the command "LOD groupings" and "create groups for mapping". The Kosambi map function was used for genetic map construction and conversion of recombination fraction into map distances in centiMorgans (cM) [41]. After preparing a framework genetic map, the remaining markers (distorted) were also integrated into the main framework map at recombination frequency ( $\partial$ ) of upto $50 \%$. The final marker positions of each LG were then used to draw final genetic map using MapChart [42].

\section{Quantitative trait locus (QTL) analysis}

Two genetic softwares were used for identification of main-effect QTLs (M-QTLs) (Windows QTLCartographer and QTLNetwork) and epistatic QTL interactions (E-QTLs) (QTLNetwork). Composite interval mapping (CIM) approach was used for identification of location and effect of M-QTLs using Windows QTLCartographer, version 2.5 [43] following the same criteria selected by Ravi et al. [26]. QTLCartographer uses a dynamic algorithm which considers various gene actions (additive and dominance), QTL-environment interactions and close linkage. Parameters such as model 6, scanning intervals of $1.0 \mathrm{cM}$ between markers and putative QTLs with a window size of $10.0 \mathrm{cM}$ were used for conducting the CIM analysis. In addition, forward-backward stepwise regression was selected for background control set by the number of marker cofactors along with 500 times permutations with 
0.05 significance level and "Locate QTLs" option to locate QTLs.

Another software, QTLNetwork program ver. 2.0 [44] which is based on a mixed linear model, was used to identify M-QTLs and E-QTLs with the first-dimensional genome scan with the option to map epistasis and the second-dimensional genome scan to detect epistatic interactions with or without single-locus effect. Parameters such as 1000 permutations, experimental-wise significance level of 0.05 for detection of QTLs with their effect, genome scan configuration (1.0 cM walk speed, $10.0 \mathrm{cM}$ testing window and filtration window size) and Monte Carlo Markov Chain (MCMC) for estimating QTL effects were selected for performing QTL analysis. QTL analysis was conducted on phenotyping data of individual year (trait_2010, trait_2011) for all the four traits namely oleic acid (C18:1), linoleic acid (C18:2), O/L ratio, and oil content.

\section{Additional files}

Additional file 1: Genetic linkage map of the S-population. This genetic map shows map location and order of all the 206 loci on the 20 linkage groups.

Additional file 2: Genetic linkage map of the T-population. This genetic map shows map location and order of all the 278 loci on the 20 linkage groups.

Additional file 3: Genetic map order in different linkage groups of the S-population.

Additional file 4: Genetic map order in different linkage groups of the T-population.

Additional file 5: Summary of main-effect QTLs (M-QTLs) identified by QTLCartographer in the S-population. This table shows details on location, flanking marker loci, LOD value, phenotypic variance explained and additive effects of 27 M-QTLs detected by QTLCartographer.

Additional file 6: Summary of main-effect QTLs (M-QTLs) identified by QTLCartographer in the T-population. This table shows details on location, flanking marker loci, LOD value, phenotypic variance explained and additive effects of 29 M-QTLs detected by QTLCartographer

Additional file 7: Summary of main-effect QTLs (M-QTLs) identified by QTLNetwork in the S-population. This table shows details on location, flanking marker loci, phenotypic variance explained and additive effects of 11 M-QTLs detected by QTLNetwork.

Additional file 8: Summary of main-effect QTLs (M-QTLs) identified by QTLNetwork in the T-population. This table shows details on location, flanking marker loci, phenotypic variance explained and additive effects of 11 M-QTLs detected by QTLNetwork.

Additional file 9: Summary of epistatatic QTLs (E-QTLs) identified by QTLNetwork in the S- and the T-populations. This table shows details on search range, $\mathrm{F}$ value, phenotypic variance explained, number of interacting loci and names interacting loci for $10 \mathrm{E}-\mathrm{QTL}$ detected by QTLNetwork.

Additional file 10: Source of markers used for construction of genetic maps for the S- and the T-populations. This table shows details on source of the markers used in this study.

Competing interests

The authors declare that they have no competing interests.

\section{Authors' contributions}

MKP participated in genotyping and phenotyping, analyzed data, and drafted and revised the manuscript. MLW and BT conducted the oil content and quality analysis. LQ, SF, and HW extracted DNA and conducted genotyping on both mapping populations. PK was involved in interpretation of results and preparation of manuscript draft. NB genotyped ahFAD2A and ahFAD2B, and was involved in experiment discussion and manuscript revision. JW helped in experimental design and manuscript revision. $\mathrm{CH}$ and AC helped in population development and manuscript revision. RKV participated in experimental design, results interpretation, manuscript draft and revision. BG made the crosses, developed the populations, conceived, planned, designed the experiments, and drafted and revised the manuscript. All authors read and approved the final manuscript.

\section{Acknowledgements}

We thank Billy Wilson, Jake Fountain, Stephanie Lee, Lucero Gutierrez and Sara Beth Pelham for technical assistance in the field and the laboratory work. A special appreciation will be to David Pinnow for helping in oil content measurement. This research was partially supported by funds provided by the USDA Agricultural Research Service, the Georgia Agricultural Commodity Commission for Peanuts, Peanut Foundation and National Peanut Board. Mention of trade names or commercial products in this publication is solely for the purpose of providing specific information and does not imply recommendation or endorsement by the U.S. Department of Agriculture. This work has been undertaken as part of the CGIAR Research Program on Grain Legumes. ICRISAT is a member of CGIAR Consortium.

\section{Author details}

US Department of Agriculture-Agricultural Research Service, Crop Protection and Management Research Unit, Tifton, GA, USA. ${ }^{2}$ International Crops Research Institute for the Semi-Arid Tropics (ICRISAT), Hyderabad, India. ${ }^{3}$ Department of Plant Pathology, University of Georgia, Tifton, GA, USA.

${ }^{4}$ US Department of Agriculture-Agricultural Research Service, Plant Genetic Resources Conservation Unit, Griffin, GA, USA. ${ }^{5}$ College of Life Science, Qingdao Agricultural University, Qingdao, China. ${ }^{6} \mathrm{College}$ of Bioscience and Biotechnology, Qiongzhou University, Sanya, China. ${ }^{7}$ Peanut Research Institute, Shandong Academy of Agricultural Sciences, Qingdao, China. ${ }^{8}$ Department of Agronomy, University of Florida, Gainesville, FL, USA. ${ }^{9}$ US Department of Agriculture-Agricultural Research Service, Crop Genetics and Breeding Research Unit, Tifton, GA, USA.

Received: 25 July 2014 Accepted: 20 November 2014

Published online: 10 December 2014

\section{References}

1. Food and Agriculture Organization (FAO): Food and Agricultural Organization of the United Nation, FAO Statistical Database. In http://faostat3.fao.org/browse/Q/*/E. 2014, data accessed on 21 ${ }^{\text {st }}$ May 2014

2. Barrientos-Priego L, Isleib TG, Pattee HE: Variation in oil content among Mexican and Peruvian hirsuta peanut landraces and Virginia-type hypogaea lines. Peanut Sci 2002, 29:72-77.

3. Ray TK, Holly SP, Knauft DA, Abbott AG, Powell GL: The primary defect in developing seed from the high oleate variety of peanut (Arachis hypogaea L.) is the absence of $\Delta 12$-desaturase activity. Plant Sci 1993 91:15-21.

4. Jung S, Swift D, Sengoku E, Patel M, Teule F, Powell G, Moore K, Abbott A The high oleate trait in the cultivated peanut (Arachis hypogaea L.): I. Isolation and characterization of two genes encoding microsomal oleoyl-PC desaturases. Mol Gen Genet 2000, 263:796-805.

5. Jung S, Powell G, Moore K, Abbott A: The high oleate trait in the cultivated peanut (Arachis hypogaea L): II. Molecular basis and genetics of the trait. Mol Gen Genet 2000, 263:806-811.

6. Yu S, Pan L, Yang Q, Min P, Ren Z, Zhang H: Comparison of the $\Delta^{12}$ fatty acid desaturase gene between high-oleic and normal-oleic peanut genotypes. J Genet Genomics 2008, 35:679-685.

7. Kavera B: Oil quality improvement in Groundnut (Arachis hypogaea L.) through induced mutagenesis. In PhD Thesis. Dharwad (India): University of Agricultural Sciences; 2008

8. O'Keefe SF, Wiley VA, Knauft DA: Comparison of oxidative stability of high- and normal-oleic peanut oils. J Am Oil Chem Soc 1993, 70:489-492. 
9. O'Byrne DJ, Knauft DA, Shireman RB: Low fat monounsaturated rich diets containing high-oleic Peanuts improve serum lipoprotein profiles. Lipids 1997, 32:687-695.

10. Yamaki T, Nagamine I, Fukumoto K, Yano T, Miyahara M, Sakurai H: High oleic peanut oil modulates promotion stage in lung tumorigenesis of mice treated with methyl nitrosourea. Food Sci Technol Res 2005, 11:231-235

11. Kris-Eterton MP, Pearson AT, Wan Y, Hargrove RL, Moriarty K, Fishell V, Etherton DT: High monounsaturated fatty acid diets lower both plasma cholesterol and triacylglycerol concentrations. Amer Soc Clin Nutr 1999, 70:1009-1015.

12. Groff JL, Gropper SS, Hunt SM: Lipids: In Advanced Nutrition and Human Metabolism. Minneapolis/St Paul MN: West Publishing; 1996:113-146.

13. Miller JF, Zimmerman DC, Vick BA: Genetic control of high oleic acid content in sunflower oil. Crop Sci 1987, 27:923-926.

14. Guo BZ, Chen CY, Chu Y, Holbrook CC, Ozias-Akins P, Stalker HT: Advances in genetics and genomics for sustainable peanut production. In Sustainable Agriculture and New Biotechnologies, edited by Benkeblia N. Boca Raton, FL: CRC Press; 2012:341-367.

15. Pandey MK, Monyo E, Ozias-Akins $P$, Liang $X$, Guimarães $P$, Nigam SN, Upadhyaya HD, Janila P, Zhang X, Guo B, Cook DR, Bertioli DJ, Michelmore R, Varshney RK: Advances in Arachis genomics for peanut improvement. Biotechnol Adv 2012, 30(3):639-651.

16. Varshney RK, Mohan SM, Gaur PM, Gangarao NVPR, Pandey MK, Bohra A, Sawargaonkar S, Kimurto PK, Janila P, Saxena KB, Fikre A, Sharma M, Pratap A, Tripathi S, Datta SK, Chaturvedi G, Anuradha A, Babbar RG, Chaudhary MB, Mhase CH, Bharadwaj S, Mannur DM, Harer PN, Guo B, Liang X, Nadarajan N, Gowda CLL: Achievements and prospects of genomics-assisted breeding in three legume crops of the semi-arid tropics. Biotechnol Adv 2013, 31:1120-1134.

17. Norden AJ, Gorbet DW, Knauft DA, Young CT: Variability in oil quality among peanut genotypes in the Florida breeding program. Peanut $\mathrm{SCl}$ 1987, 14:7-11.

18. Gorbet DW, Knauft DA: Registration of 'SunOleic 95R' peanut. Crop Sci 1997, 37:1392

19. Gorbet DW, Knauft DA: Registration of 'SunOleic 97R' peanut. Crop Sci 2000, 40:1190-1191.

20. Eskandari M, Cober ER, Rajcan I: Genetic control of soybean seed oil: I. QTL and genes associated with seed oil concentration in RIL populations derived from crossing moderately high-oil parents. Theor Appl Genet 2013, 126:483-495.

21. Qin H, Feng S, Chen C, Guo Y, Knapp S, Culbreath A, He G, Wang ML, Zhang X, Holbrook CC, Ozias-Akins P, Guo B: An integrated genetic linkage map of cultivated peanut (Arachis hypogaea L.) constructed from two RIL populations. Theor Appl Genet 2012, 124:653-664.

22. Bolton GE, Sanders TH: Effect of roasting oil composition on the stability of roasted high-oleic peanuts. J Am Oil Chem Soc 2002, 79:129-132.

23. Beavis WD: QTL Analyses: Power, precision and accuracy. In Molecular Dissection of Complex Traits. Edited by Paterson AH. Boca Raton: CRC Press; 1998.

24. Raghavan C, Collard BCY: Effect of small mapping population sizes on reliability of quantitative trait locus (QTL) mapping. Afric J Biotech 2012, 11(47):10661-10674.

25. Varshney RK, Bertioli DJ, Moretzsohn MC, Vadez V, Krishnamurty L, Aruna R, Nigam SN, Ravi K, He G, Knapp SJ, Hoisington DA: The first SSR based genetic linkage map for cultivated groundnut (Arachis hypogaea L.). Theor Appl Genet 2009, 118:729-739.

26. Ravi K, Vadez V, Isobe S, Mir RR, Guo Y, Nigam SN, Gowda MVC, Radhakrishnan T, Bertioli DJ, Knapp SJ, Varshney RK: Identification of several small main-effect QTLs and a large number of epistatic QTLs for drought tolerance related traits in groundnut (Arachis hypogaea L.). Theor Appl Genet 2011, 122:1119-1132.

27. Gautami B, Pandey MK, Vadez V, Nigam SN, Ratnakumar P, Krishnamurthy L, Radhakrishnan T, Gowda MVC, Narasu ML, Hoisington DA, Knapp SJ, Varshney RK: Quantitative trait locus analysis and construction of consensus genetic map for drought tolerance traits based on three recombinant inbred line populations in cultivated groundnut (Arachis hypogaea L.). Mol Breed 2012, 32(2):757-772.

28. Sujay V, Gowda MVC, Pandey MK, Bhat RS, Khedikar YP, Nadaf HL, Gautami B, Sarvamangala C, Lingaraju S, Radhakrishan T, Knapp SJ, Varshney RK: Quantitative trait locus analysis and construction of consensus genetic map for foliar disease resistance based on two recombinant inbred line populations in cultivated groundnut (Arachis hypogaea L.). Mol Breed 2012, 32(2):773-788

29. Sarvamangala C, Gowda MVC, Varshney RK: Identification of quantitative trait loci for protein content, oil content and oil quality for groundnut (Arachis hypogaea L.). Field Crop Res 2011, 122:49-59.

30. Pandey MK, Upadhyaya HD, Rathore A, Vadez V, Sheshshayee MS, Sriswathi M, Govil M, Kumar A, Gowda MVC, Sharma S, Hamidou F, Kumar VA, Khera P, Bhat R, Khan AW, Singh S, Li H, Monyo E, Nadaf HL, Mukri G, Jackson SA Guo B, Liang X, Varshney RK: Genomewide association studies for 50 agronomic traits in peanut using the 'reference set' comprising 300 genotypes from 48 countries of semi-arid tropics of the world. PLOS ONE 2014. doi:10.1371/journal.pone.0105228.

31. Zhao J, Dimov Z, Becker HC, Ecke W, Mollers C: Mapping QTL controlling fatty acid composition in a doubled haploid rapeseed population segregating for oil content. Mol Breed 2008, 21:115-125

32. Pham A-T, Shannon JG, Bilyeu KD: Combinations of mutant FAD2 and $F A D 3$ genes to produce high oleic acid and low linolenic acid soybean oil. Theor App/ Genet 2012, 125:503-515.

33. Liu Z, Feng S, Pandey MK, Chen X, Culbreath AK, Varshney RK, Guo BZ: Identification of expressed resistance gene analogs (RGAs) from peanut (Arachis hypogaea L.) expressed sequence tags (ESTs). J Integr Plant Biol 2013, 55(5):453-461.

34. Varshney RK, Pandey MK, Janila P, Nigam SN, Sudini H, Gowda MVC, Sriswathi M, Radhakrishnan T, Manohar SS, Nagesh P: Marker-assisted introgression of a QTL region to improve rust resistance in three elite and popular varieties of peanut (Arachis hypogaea L.). Theor Appl Genet 2014, 127(8):1771-1781.

35. Chu Y, Holbrook CC, Ozias-Akins P: Two alleles of ahFAD2B control the high oleic acid trait in cultivated peanut. Crop Sci 2009, 49:2029-2036.

36. Wang ML, Chen CY, Davis J, Guo B, Stalker HT, Pittman RN: Assessment of oil content and fatty acid composition variability in different peanut subspecies and botanical varieties. Plant Genet Resour 2009, 8:71-73.

37. Wang ML, Barkley NA, Chen Z, Pittman RN: FAD2 gene mutations significantly alter fatty acid profiles in cultivated peanuts (Arachis hypogaea). Biochem Genet 2011, 49:748-759.

38. Wilson JN, Baring MR, Burow MD, Rooney WL, Simpson CE: Diallel analysis of oil production components in peanut (Arachis hypogaea L.). Int/ J Agron 2013, 2013:975701.

39. Barkley NA, Isleib TG, Wang ML, Pittman RN: Genotypic effect of ahFAD2 on fatty acid profiles in six segregating peanut (Arachis hypogaea $\mathrm{L}$ ) populations. BMC Genet 2013, 14:62.

40. Holbrook CC, Culbreath AK: Registration of 'Tifrunner' peanut. J Plant Registr 2007, 1:124.

41. Kosambi DD: The estimation of map distance from recombination values. Ann Eugen 1944, 12:172-175.

42. Voorrips RE: Mapchart: software for the graphical presentation of linkage maps and QTLs. J Hered 2002, 93:77-78.

43. Wang S, Basten CJ, Zeng ZB: Windows QTL cartographer 2.5. Raleigh, NC: Department of Staristics, North Carolina State University, USA; 2011.

44. Yang J, Hu CC, Ye XZ, Zhu J: QTLNetwork 2.0. In Hangzhou, China: Institute of Bioinformatics, Zhejiang University; 2005. Available at http://ibi.zju.edu.cn/ software/qtinetwork.

\section{Submit your next manuscript to BioMed Central and take full advantage of:}

- Convenient online submission

- Thorough peer review

- No space constraints or color figure charges

- Immediate publication on acceptance

- Inclusion in PubMed, CAS, Scopus and Google Scholar

- Research which is freely available for redistribution 